\title{
DEPTOR Deficiency-Mediated mTORc1 Hyperactivation in Vascular Endothelial Cells Promotes Angiogenesis
}

\author{
Yan Ding ${ }^{\mathrm{ab}}$ Lanlan Shan ${ }^{\mathrm{a}}$ Wenqing Nai ${ }^{\mathrm{a}}$ Xiaojun Lin ${ }^{\mathrm{c}}$ Ling Zhou ${ }^{\mathrm{d}}$ \\ Xiaoying Dong ${ }^{d}$ Hongyuan $W^{a}{ }^{a}$ Min Xiaoc Xuejuan Zhou ${ }^{c}$ Linlin Wang ${ }^{d}$ \\ Ting Lic You Fu ${ }^{a}$ Yijun Lin ${ }^{a}$ Chunhong Jia ${ }^{c}$ Meng Dai ${ }^{a}$ Xiaochun Baice \\ aFrom the Department of Health Management, Nanfang Hospital, Southern Medical University, \\ Guangzhou, Guangdong, 'Department of Endocrinology, Wuhan General Hospital of Guangzhou \\ Command, Wuhan, Hubei Province, Southern Medical University, Guangzhou, Guangdong, \\ 'Department of Cell Biology, School of Basic Medical Sciences, Southern Medical University, \\ Guangzhou, Guangdong, dDepartment of Oncology, Nanfang Hospital, Southern Medical University, \\ Guangzhou, Guangdong, eState Key Laboratory of Organ Failure Research, Department of Cell Biology, \\ School of Basic Medical Sciences, Southern Medical University, Guangzhou, China
}

\section{Key Words}

Angiogenesis • DEPTOR • mTORC1 • Vascular endothelial cell • VEGF • HIF-1 $\alpha$

\begin{abstract}
Background/Aims: The mechanistic target of rapamycin (mTOR) signaling pathway is essential for angiogenesis and embryonic development. DEP domain-containing mTOR-interacting protein (DEPTOR) is an mTOR binding protein that functions to inhibit the mTOR pathway. In vitro experiments suggest that DEPTOR is crucial for vascular endothelial cell (EC) activation and angiogenic responses. However, knowledge of the effects of DEPTOR on angiogenesis in vivo is limited. This study aimed to determine the role of DEPTOR in tissue angiogenesis and to elucidate the molecular mechanisms. Methods: Cre/loxP conditional gene knockout strategy was used to delete the Deptor gene in mouse vascular ECs. The expression or distribution of cluster of differentiation 31 (CD31), vascular endothelial growth factor (VEGF) and hypoxia inducible factor-1 alpha (HIF-1 $\alpha$ ) were detected by immunohistochemical staining or western blot. Tube formation assay was used to measure angiogenesis in vitro. Results: Deptor knockdown led to increased expression of CD31, VEGF and HIF-1 $\alpha$ in heart, liver, kidney and aorta. After treatment with rapamycin, their expression was significantly downregulated. In vitro, human umbilical vein endothelial cells (HUVECs) were transfected with DEPTOR-specific small interfering RNA (siRNA), which resulted in a significant increase in endothelial tube formation and migration rates. In contrast, DEPTOR overexpression markedly reduced the expression of CD31, VEGF and HIF-1 $\alpha$. Conclusions: Our findings demonstrated that deletion of the Deptor gene in vascular ECs resulted in upregulated expression of CD31 and HIF-1 $\alpha$ and further stimulated the expression of VEGF which promoted angiogenesis, indicating that
\end{abstract}




\section{Cellular Physiology Cell Physiol Biochem 2018;46:520-531 and Biochemistry Published online: April 03, $2018 \quad \begin{aligned} & \text { D 2018 The Authors } \\ & \text { www.karger.com/cpb }\end{aligned}$}

Ding et al.: DEPTOR Deletion in Endothelial Cells Promotes Angiogenesis

disruption of normal angiogenic pathways may occur through hyperactivation of the mTORC1/ HIF-1 $\alpha /$ VEGF signaling pathway.

\section{Introduction}

Angiogenesis is the physiological process by which new blood vessels sprout from preexisting vessels [1]. It is a normal and vital process in growth and development, as well as in wound healing [2]. In contrast, pathological angiogenesis is observed in a wide range of diseases, including tumor growth, lipid metabolism disorders and chronic inflammation, as a result of excessive pro-angiogenic signals and a lack of sufficient factors to mediate vessel maturation [3]. It is known that vessels in the embryo develop from endothelial progenitors, whereas sprouting of vessels in the adult results only from division of differentiated endothelial cells (ECs) [4]. Tightly regulated and intricately interconnected signaling pathways control the proliferation, sprouting and migration of ECs during vasculogenesis and angiogenesis. At the heart of this signaling network are vascular endothelial growth factors (VEGFs). VEGFs play an important role in promoting angiogenesis and maintaining the integrity of endothelium [5, 6]. VEGF production and signaling are partly dependent on the induction of hypoxia inducible factor-1 alpha (HIF-1 $\alpha$ ) expression by mechanistic target of rapamycin (mTOR) [7, 8]. The inhibition of HIF-1 $\alpha$-mediated VEGF expression can suppress neovascularization [9].

mTOR has been shown to function in vascular EC proliferation and migration in vitro [10], and is also involved in tumor angiogenesis, wound healing angiogenesis and leukocyteinduced angiogenesis [11-13]. mTOR is a serine/threonine protein kinase known as mTOR Complex 1 (mTORC1) and 2 (mTORC2)[14]. mTORC1 promotes protein synthesis in part by phosphorylating p70S6 kinase which can phosphorylate ribosomal protein S6 (PS6) and eukaryotic translation initiation factor 4E-binding protein 1 (4E-BP1). mTORC2 controls cell proliferation and survival [15]. mTORC1 is sensitive to rapamycin, but mTORC2 is not [16]. mTOR activation is tightly regulated by several negative feedback loops and by distinct proteins. One such regulatory protein is DEPTOR, which is an mTOR binding protein and functions to inhibit the mTORC1 and mTORC2 pathways [17]. It has been reported that DEPTOR regulates vascular EC activation and plays an important role in pro-inflammatory and angiogenic response in vitro [18]. However, the role of DEPTOR in angiogenesis in vivo remains poorly understood.

In our study, we demonstrated that DEPTOR deficiency in vascular ECs in mice was associated with mTORC1 signaling pathway activation and contributed to extensive angiogenesis in liver, kidney and heart. To our knowledge, our study was the first to illustrate the relationship between DEPTOR and angiogenesis in vivo.

\section{Materials and Methods}

\section{Mice, Husbandry and Genotyping}

All animal experiments were approved by the Animal Care and Use Committee of Southern Medical University (Guangzhou, China). All animals received humane care and the study protocols were conducted according to the institution's guidelines. Tek-Cre mice (Jax no. 004128) were imported directly from The Jackson Laboratory (Bar Harbor, ME, USA). Deptor ${ }^{\text {tm1a (EUComm)Wtsi }}$ embryonic stem cell clone EPD0556_1_ H09 was purchased from the European Conditional Mouse Mutagenesis Program (EUCOMM ID:41725, Germany). Germline-transmitting chimeric mice were produced by the Shanghai Model Organisms Center, Inc. (Shanghai, China). The Tek-Cre mice were crossed with Deptor ${ }^{\mathrm{n} / \mathrm{l}}$ mice to generate Tek-Cre $/$ Deptor ${ }^{\mathrm{n} / \mathrm{+}}$ mice. These heterozygotes were further crossed with Deptor ${ }^{\mathrm{n} / \mathrm{fl}}$ mice to produce Tek-Cre ${ }^{+} /$Deptor $^{\mathrm{n} / \mathrm{fl}}$ mice. These mice with vascular EC-specific deletion of Deptor were designated as knockout (KO) mice. The Crenegative mice from the same litter were referred to as wild type (WT) mice. DNA isolated from tail biopsies was used for genotyping with polymerase chain reaction (PCR). The primer sequences for Tek were 5'-GCG 


\section{Cellular Physiology Cell Physiol Biochem 2018;46:520-531 \begin{tabular}{ll|l} 
DOI: 10.1159/000488619 & (c) 2018 The Author(s). Published by S. Karger AG, Basel
\end{tabular}

Ding et al.: DEPTOR Deletion in Endothelial Cells Promotes Angiogenesis

GTC TGG CAG TAA AAA CTA TC-3' and 5'-GTG AAA CAG CAT TGC TGC CAC TT-3'; for Deptor, the primer sequences were $5^{\prime}$-GGA AGT GAA GAC CTG TGA AGA TAA GAG-3' and 5'-GGA AGT GAA GAC CTG TGA AGA TAA GAG-3'. Rapamycin was administered to KO and WT mice (8-12 weeks old) at a dosage of $1 \mathrm{mg} / \mathrm{kg} /$ day by intraperitoneal injection for 28 days.

\section{Cell Line Culture}

Human umbilical vein ECs (HUVECs) were obtained from the American Type Culture Collection (Rockville, MD, USA). The cells were cultured in EC basal medium 2 (EBM2) containing low serum (2\% fetal bovine serum) and EC growth supplement (Promo Cell, Heisenberg, Germany) in a humidified atmosphere $\left(5 \% \mathrm{CO}_{2}\right)$ at $37^{\circ} \mathrm{C}$.

\section{Western Blot Analysis}

The cells were collected and lysed in RIPA buffer, and incubated on ice for $30 \mathrm{~min}$. The protein concentration was quantified using a BCA Protein Assay Kit (Thermo Fisher Scientific, Massachusetts, USA). Protein extracts were separated by gel electrophoresis, transferred to nitrocellulose membranes and subsequently incubated with the following antibodies: anti-DEPTOR (1:2000; Santa Cruz Biotechnology, Dallas, TX, USA, sc-398169), anti-pS6 (S235/236 1:2000; Cell Signaling Technology, Boston, MA, USA, 4858), anti-phosphorylated ribosomal protein S6 kinase (p-S6K; T389, 1:2000; Cell Signaling Technology, 9205s), anti-ribosomal protein S6 kinase (S6K; 1:2000; Cell Signaling Technology, 9202s), anti-S6 (1:3000; Santa Cruz Biotechnology, sc-74459), anti- $\beta$-Actin (1:3000; Santa Cruz Biotechnology, sc-47778 ), antiCD31 (1:1000, R\&D Systems, Minneapolis, MN, USA, AF3628), anti-VEGF (1:1, 000; Abcam, Cambridge, UK, ab46154), anti-VEGFR-2 (1:1000; Abclonal Technology, Boston, MA, USA, A11127 ), anti-HIF-1 $\alpha$ (1:500; Santa Cruz Biotechnology, sc-13515) and anti-glyceraldehyde-3-phosphate dehydrogenase (GAPDH) (1:4000; Cell Signaling Technology, KM9002). Thereafter, the blots were washed three times with TBST (50 $\mathrm{mM}$ Tris, $150 \mathrm{mM} \mathrm{NaCl}, 0.05 \%$ Tween 20, adjusted to $\mathrm{pH} 7.6$ with $\mathrm{HCl}$ ) for $5 \mathrm{~min}$, and then incubated with horseradish peroxidase-conjugated secondary antibodies and visualized with the Odyssey Infrared Imaging System (LI-COR Biosciences, Nebraska, USA). The results were analyzed quantitatively by densitometry using Image Pro Plus 6.0 software (Media Cybernetics, Rockville, MD, USA).

\section{Tissue Collection and Histological Analysis}

Hearts, livers, kidneys and aortas were removed from mice and weighed, fixed for $24 \mathrm{~h}$ in $4 \%$ paraformaldehyde, embedded in paraffin, sliced into $5 \mu \mathrm{m}$-thick sections and stained with hematoxylin and eosin as previously described [19]. Immunohistochemical (IHC) staining was performed using standard procedures. Mouse heart, liver and kidney sections were deparaffinized, rehydrated and incubated with CD31 antibody (1:200; R\&D Systems, AF3628), VEGF antibody (1:100; Abcam, ab46154) or HIF-1 $\alpha$ antibody (1:100; Santa Cruz Biotechnology, sc-13515) overnight at $4^{\circ} \mathrm{C}$. After incubation with primary antibodies, the sections were incubated with horseradish peroxidase-conjugated anti-immunoglobulin secondary antibodies (Jackson Immuno Research, West Grove, PA, USA) and visualized with 3, 3'-diaminobenzidine. The slides were counterstained with hematoxylin. The area of positive staining was measured in five different images taken at 400× magnification on each slide and quantified using Image Pro Plus 6.0 software. Immunofluorescent (IF) staining was performed following standard procedures. The sections were incubated with DEPTOR antibody (1:200; Santa Cruz Biotechnology, sc-398169) or pS6 antibody (S235/236; 1:200; Cell Signaling Technology, 4858). After incubation with primary antibodies, the sections were washed with phosphate-buffered saline and incubated with the appropriate fluorescent secondary antibodies. Sections were mounted with ProLong ${ }^{\mathrm{TM}}$ Gold Antifade Mountant with DAPI (Thermo Fisher Scientific) and imaged by FluoView FV1000 confocal microscopy (Olympus, Shinjuko, Japan).

\section{Small Interfering RNA Knockdown and DNA transfection}

siRNA was transfected to knockdown DEPTOR in HUVECs using Lipofectamine RNAi MAX (Invitrogen, Carlsbad, CA, USA), according to the manufacturer's instructions. The efficiency of transfection was measured by western blot. The sequences of siRNA used in this study were as follows [20].

SiRNA DEPTOR \#1, 5'-GCCATGACAATCGGAAATCTA-3'; SiRNA DEPTOR \#2, 5' -GCAAGGAAGACATTCACGATT- ${ }^{\prime}$; non-specific siRNA used as control, 5'-UUCUCCGAACGUGUCACGUTT-3'. 


\section{Cellular Physiology Cell Physiol Biochem 2018;46:520-531 \begin{tabular}{c|c|c|} 
DOI: 10.1159/000488619 & $\begin{array}{l}\text { O 2018 The Author(s). Published by S. Karger AG, Basel } \\
\text { www.karger.com/cpb }\end{array}$ \\
\hline
\end{tabular}}

Ding et al.: DEPTOR Deletion in Endothelial Cells Promotes Angiogenesis

To overexpress DEPTOR, HUVECs were transfected with FLAG-DEPTOR plasmid (Addgene, Cambridge, MA, USA, \#21334) using Lipofectamine 3000 (Invitrogen, California, USA) according to the manufacturer's instructions.

\section{EC Tube Formation Assay}

HUVECs were transfected with control or DEPTOR siRNA following culture for $30 \mathrm{~h}$, and then treated with or without rapamycin $(10 \mathrm{ng} / \mathrm{mL}$ for $18 \mathrm{~h})$ before running the tube formation assay. The cells were then seeded in 96 well plates coated with matrigel (BD Bioscience, NY, USA) at a density of $1 \times 10^{5}$ cells per well in EBM2 containing 2\% FBS and EC growth supplement for $12 \mathrm{~h}$ at $37^{\circ} \mathrm{C}$. After a wash step with phosphate buffer saline (PBS), the cells were fixed with 4\% paraformaldehyde. Images were taken on an IX71 Olympus microscope, and branch point quantifications were analyzed using Image Pro Plus 6.0 software.

\section{In vitro migration scratch assay.}

HUVECs were seeded at a density of $1 \times 10^{5}$ cells per well in 24 well plates. Confluent HUVECs were serum-deprived for $16 \mathrm{~h}$, and a linear wound was created in the monolayers by scratching with a sterile pipette tip. The cells were then washed with PBS three times and cultured for 0 and $18 \mathrm{~h}$ before being photographed with a microscope. The extent of wound healing was calculated by analyzing the percentage of cell coverage over the scratch zone at 0 and $18 \mathrm{~h}$ in at least 3 separate experiments.

\section{Statistical Analysis}

All experiments were performed in triplicate. All data were expressed as means \pm standard error of the mean (SEM). The data for each group were analyzed using two-way ANOVA with SPSS ver. 13.0 software (IBM-SPSS, Inc., Chicago, IL, USA). $P<0.05$ was considered as statistical significance.

\section{Results}

Generation of Deptor conditional knockout mice

To address the potential role of DEPTOR in the homeostasis of vascular ECs, mice containing a floxed Deptor allele were crossed with transgenic mice expressing Cre under the control of the endothelial-specific Tek promoter [21]. The resultant Cremediated deletion of Deptor exon 2 led to a frame-shift mutation that produced a nonfunctional protein (Fig. 1A). Genomic DNA from tail tissue was genotyped by PCR analysis to confirm the presence of the Deptor and Cre genes (Fig. 1B). IF staining indicated that DEPTOR expression was decreased in vascular ECs in KO mice comparing with WT

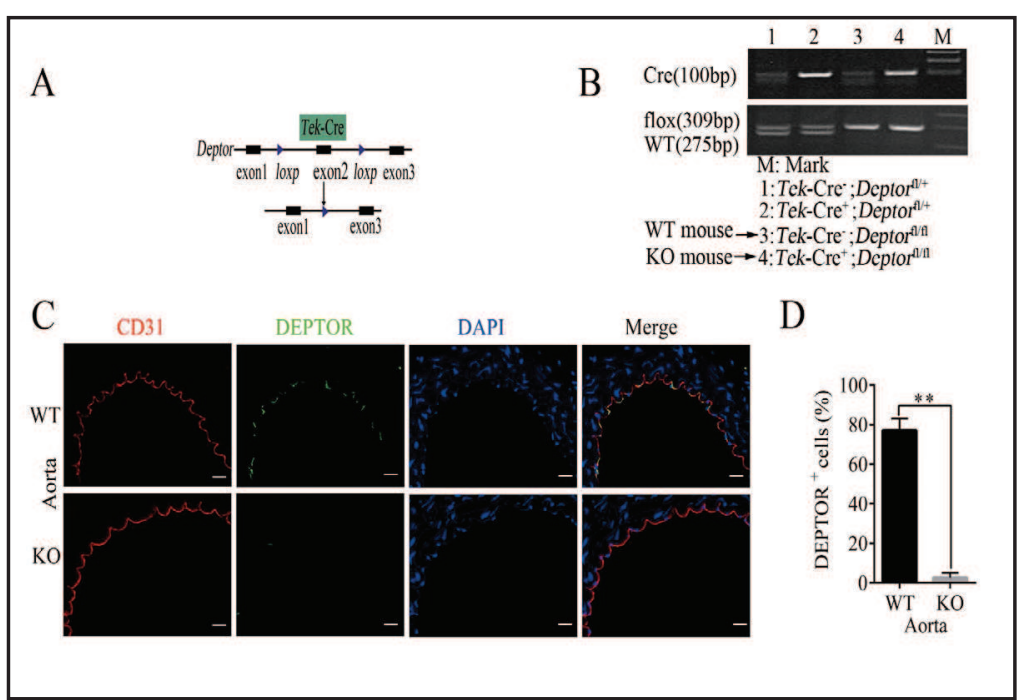

Fig. 1. Generation of EC-specific Deptor knockout mice. (A) Illustration of the Deptor exons of mutant and floxed (fl) alleles. (B) Genotyping the F2 offspring by PCR after mating the transgenic mice. Lane 4: KO mouse; lane 3: WT mouse; M: DNA marker. (C) IF detected the expression of DEPTOR (green) and CD31 (red) in thoracic aorta. Nuclei are shown in blue (DAPI staining). White bar $=20 \mu \mathrm{m}$. (D) Quantitation of DEPTOR-positive cells. $* * \mathrm{P}<0.01, \mathrm{n}=3$. 


\section{Cellular Physiology Cell Physiol Biochem 2018;46:520-531 \begin{tabular}{c|c|c|c|c|}
\hline DOI: 10.1159/000488619 & (0) 2018 The Author(s). Published by S. Karger AG, Basel \\
and Biochemistry Published
\end{tabular}

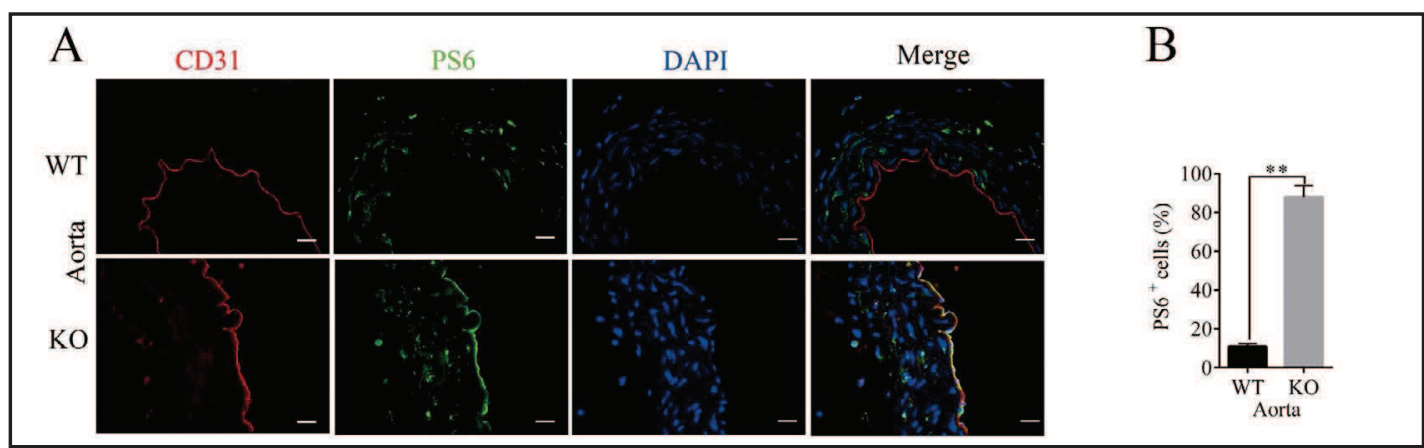

Fig. 2. Loss of DEPTOR activated mTOR signaling in ECs. (A) IF staining of pS6 (green) in aorta vascular ECs marked by CD31 staining (red) in WT and KO littermates at 2 months of age. Nuclei are shown in blue (DAPI staining). White bar $=20 \mu \mathrm{m}$. (B) Quantitation of pS6-positive cells. $* * \mathrm{P}<0.01, \mathrm{n}=3$.

mice as shown in Fig.1C and D. Cluster of differentiation 31 (CD31) was used primarily to show the presence of endothelial cells, which helped to evaluate the degree of angiogenesis [22]. Taken together, the results showed that there was DEPTOR deficiency in ECs of Tek$\mathrm{Cre}^{+} /$Deptor $^{\mathrm{f} / \mathrm{fl}}$ mice compared with WT mice.

\section{EC-specific deletion of Deptor activated mTORC1 signaling}

Because DEPTOR was an mTOR inhibitor [23], the activity of mTORC1 was examined at first. When the mTOR signaling pathway was activated, the phosphorylation of PS6 (S235/236) was upregulated [23]. IF staining indicated that the level of PS6 (S235/236) was elevated in aorta vascular ECs in KO mice compared with WT control littermates (Fig. 2A and 2B). The same result was obtained in heart, liver and kidney tissue.

EC-specific deletion of Deptor increased angiogenesis, and rapamycin reversed this effect

There were no obvious differences in the physical appearance or body weights of KO and WT mice. Similarly, the histomorphology of heart, liver and kidney in KO and WT mice showed no significant differences (Fig. 3A). Previous studies suggested that the mTORC1 pathway plays an important role in angiogenesis [24, 25]. As shown in Fig. 3B and 3C, CD31 IHC staining was significantly increased in KO mouse tissues including heart, liver and kidney compared with WT mice. However, when KO mice were treated with rapamycin, CD31 IHC staining was decreased and rapamycin treatment had no significant effect on WT mice. These findings indicated that angiogenesis was enhanced in the KO mice and that activation of the mTOR pathway due to loss of DEPTOR may have contributed to this.

\section{Increased expression of VEGF in KO mice was reversed by rapamycin treatment}

A number of studies have suggested that VEGF has a close relationship with angiogenesis $[26,27]$, and mTORC1 has been associated with VEGF expression. As expected, IHC staining showed that expression of VEGF increased significantly in the heart, liver, kidney and aorta in KO mice compared with WT mice, as shown in Fig. 4A and 4B. However, following treatment with rapamycin, staining of VEGF was decreased sharply $(P<0.01)$, and rapamycin treatment alone had no significant effect on WT mice (Fig. 4A, B). Collectively, mTORC1 activation due to DEPTOR knockdown enhanced VEGF synthesis, promoting angiogenesis.

\section{Increased expression of HIF-1 $\alpha$ in KO mice was reduced by rapamycin treatment}

HIF- $1 \alpha$ levels are subject to complex translational controls operating through nutrient and cellular energy-sensing mTOR complexes [28], and VEGF production is partially dependent on mTORC1-induced HIF-1 $\alpha$ expression [29]. As shown in Fig. 5A and 5B, levels of HIF- $1 \alpha$ were significantly increased in KO mice compared with WT mice. Treatment with rapamycin reduced the level of HIF-l $\alpha$ in KO mice. These results suggested that loss of DEPTOR promoted activation of mTORC1 and increased HIF-1 $\alpha$ expression. 


\section{Cellular Physiology Cell Physiol Biochem 2018;46:520-531 \begin{tabular}{l|l} 
and Biochemistry Published on/ine: Apri103, 2018 & $\begin{array}{l}\text { () 2018 The Author(s). Published by S. Karger AG, Basel } \\
\text { www.karger.com/cpb }\end{array}$
\end{tabular}}

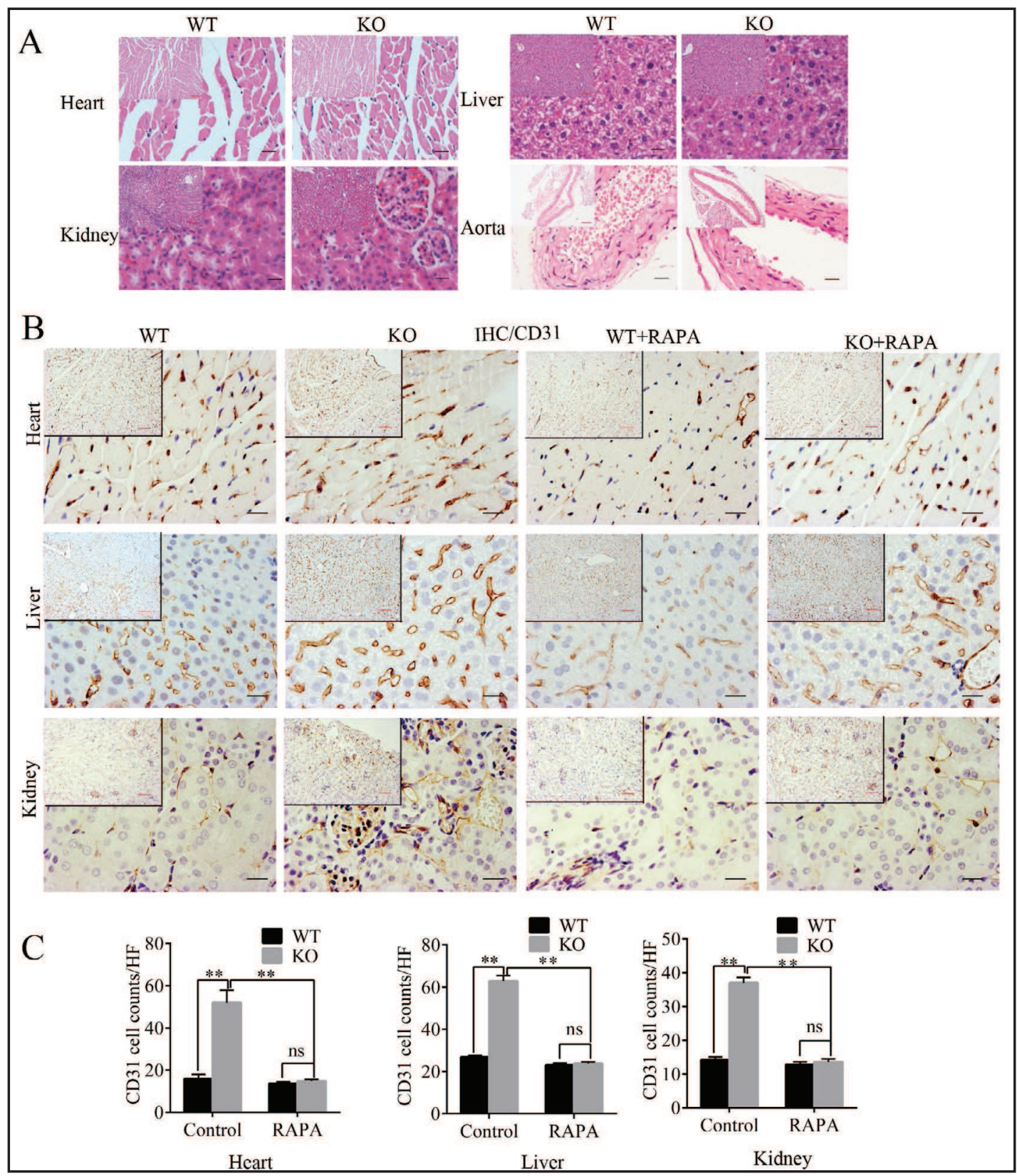

Fig. 3. EC-specific deletion of Deptor increased tissue angiogenesis which was reduced by rapamycin treatment. (A) Histological examination of heart, liver and kidney between KO and WT mice using HE staining. Black bar $=20 \mu \mathrm{m}$, red bar $=100 \mu \mathrm{m}$. (B) IHC staining of CD31 in the heart, liver and kidney of KO and WT mice with and without rapamycin treatment. Black bar $=20 \mu \mathrm{m}$, red bar $=100 \mu \mathrm{m}$. (C) Quantitation of CD31-positive cells in the four groups. NS: no significant differences, $\mathrm{P}>0.05 ;{ }^{* *} \mathrm{P}<0.01, \mathrm{n}=5$.

\section{Functional effects of DEPTOR on the mTORC1/HIF-1 $\alpha /$ VEGF pathway in vitro}

In order to explore the underlying mechanism of DEPTOR, HUVECs were used in vitro. First, HUVECs were transfected with DEPTOR siRNA and the expression of HIF- $1 \alpha$, CD31, VEGF, VEGFR-2, DEPTOR, S6, pS6 (235/236), S6K and pS6K (T389) were detected by western blot. As shown in Fig. 6A and 6B, knockdown of DEPTOR in HUVECs led to a marked increase in phosphorylation of pS6K and pS6. Similarly, the expression of CD31, VEGF and HIF- $1 \alpha$ was also increased significantly. Under the same conditions, when the cells were treated with rapamycin, the increase in phosphorylation of pS6K and pS6 was inhibited, 


\section{Cellular Physiology Cell Physiol Biochem 2018;46:520-531 \begin{tabular}{ll|l} 
and Biochemistry Published online: Apri 03, 2018 & $\begin{array}{l}\text { ( ) 2018 The Author(s). Published by S. Karger AG, Basel } \\
\text { www.karger.com/cpb }\end{array}$
\end{tabular}}

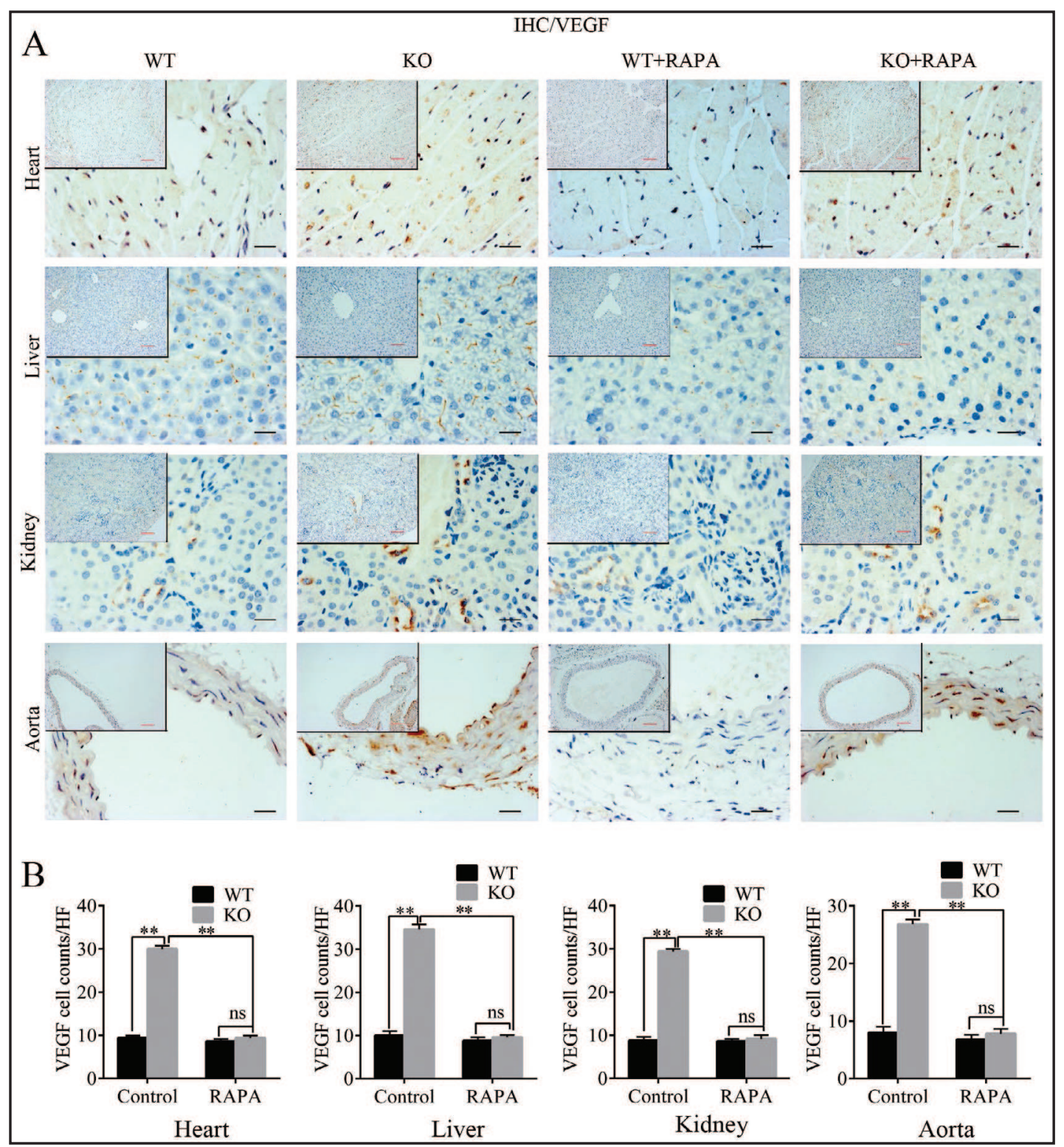

Fig. 4. Increased expression of VEGF in Deptor KO mice was reversed by rapamycin treatment. (A) IHC staining of VEGF in the heart, liver, kidney and aorta of KO mice and WT littermates with and without rapamycin treatment. Black bar $=20 \mu \mathrm{m}$, red bar $=100 \mu \mathrm{m}$. (B) Quantitation of VEGF-positive cells in the four groups. NS: no significant differences, $\mathrm{P}>0.05 ; * * \mathrm{P}<0.01, \mathrm{n}=5$.

and the expression of CD31, VEGF and HIF-1 $\alpha$ was markedly reduced. VEGFR-2 expression did not change significantly. Endothelial tube formation and migration scratch assay were also performed. HUVECs were transfected with control or DEPTOR siRNA, then treated with or without rapamycin. The efficiency of DEPTOR knockdown was first tested by western blot (Fig. 6C). As shown in Fig. 6D and 6E, small tube formation and migration ability in HUVECs increased after transfection with DEPTOR siRNA, and this trend could be reversed by rapamycin treatment. These observations suggested that loss of DEPTOR resulted in activation of the mTORC1/HIF-1 $\alpha$ /VEGF pathway which contributed to angiogenesis, while rapamycin, a specific inhibitor of mTOR, inhibited the activity of this pathway.

HUVECs were transfected with FLAG-DEPTOR, then treated with or without rapamycin. DEPTOR overexpression led to an increase in DEPTOR expression and a decrease in 


\section{Cellular Physiology Cell Physiol Biochem 2018;46:520-531 \begin{tabular}{l|l} 
and Biochemistry \\
Dublished online: April 03, 2018 & $\begin{array}{l}\text { O } 2018 \text { The Author(s). Published by S. Karger AG, Basel } \\
\text { www.karger.com/cpb }\end{array}$ \\
\cline { 2 - 3 }
\end{tabular}}

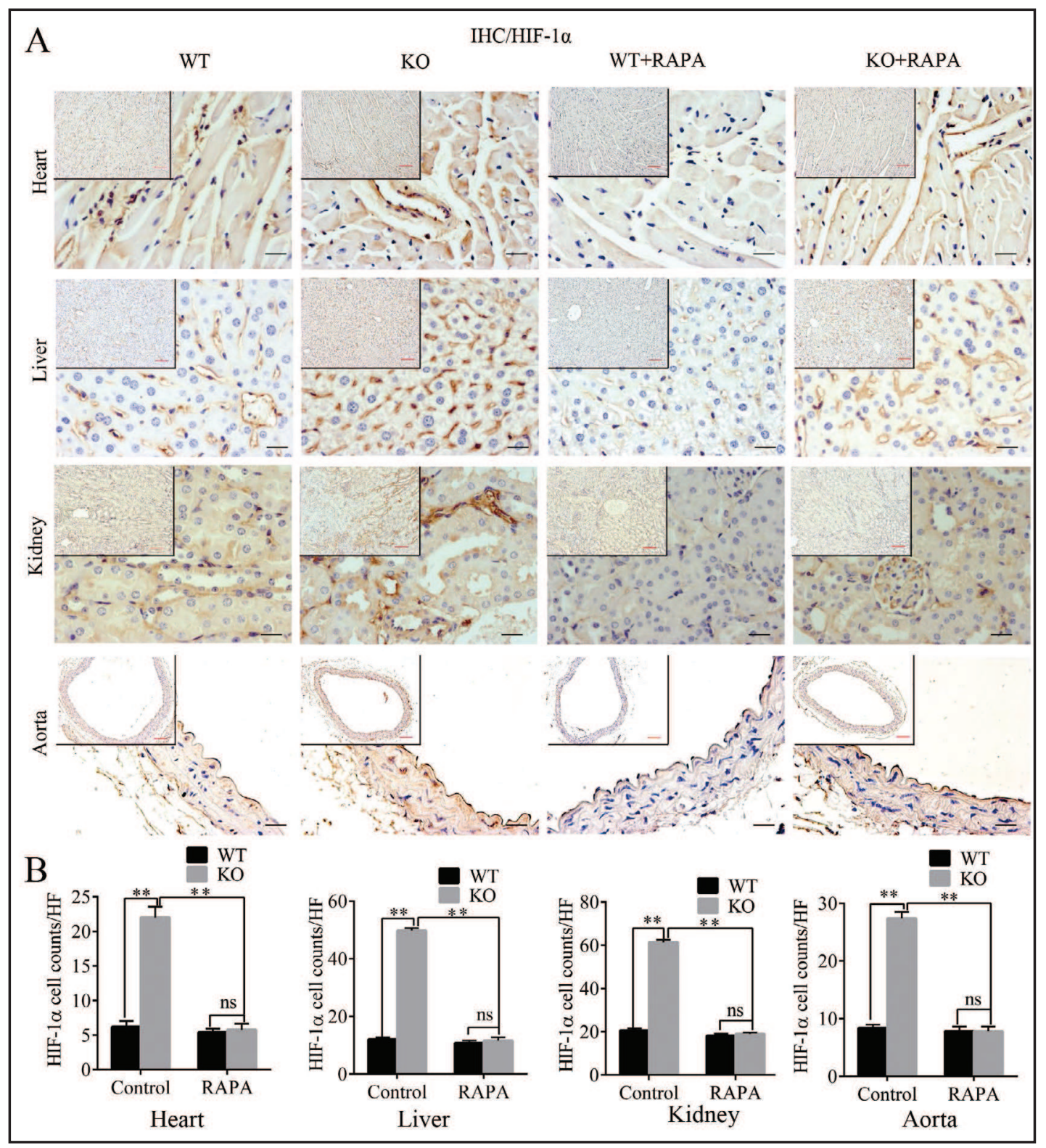

Fig. 5. Increased expression of HIF- $1 \alpha$ in Deptor KO mice was reduced by rapamycin treatment. (A) IHC staining of HIF- $1 \alpha$ in the heart, liver, kidney and aorta of KO mice and WT littermates with and without rapamycin treatment. Black bar $=20 \mu \mathrm{m}$, red bar $=100 \mu \mathrm{m}$. (B) Quantitation of HIF-1 $\alpha$-positive cells in the four groups. NS: no significant differences, $\mathrm{P}>0.05 ; * * \mathrm{P}<0.01, \mathrm{n}=5$.

phosphorylation of pS6K, pS6, and CD31, as well as decreased expression of VEGF and HIF$1 \alpha$, and this trend could be reversed by treatment with rapamycin $(10 \mathrm{ng} / \mathrm{mL}$ for $18 \mathrm{~h}$; Fig. 7A and 7B).

\section{Discussion}

DEPTOR is an mTORC1 inhibitor [30,31], which is closely related to cell proliferation, inflammation, obesity, and cancer [32,33] and directly connected with cardiovascular disease $[34,35]$. One study reported that DEPTOR regulates vascular EC activation and contributes to proinflammatory and angiogenic responses in vitro [18]. Our study examined the role of 


\section{Cellular Physiology Cell Physiol Biochem 2018;46:520-531 \begin{tabular}{ll|l}
\hline DOI: 10.1159/000488619 & 02018 The Author(s). Published by S. Karger AG, Basel \\
\cline { 2 - 3 }
\end{tabular} and Biochemistry Published online: April 03, 2018 www.karger.com/cpb}

Fig. 6. Functional effects of DEPTOR on the mTORC1/HIF-1 $\alpha /$ VEGF pathway in vitro. (A) Western blot analysis of CD31, VEGF, VEGFR-2, HIF-1 $\alpha$, pS6K1 (T389), pS6 (235/236), S6K1, S6 and GAPDH. GAPDH was included as a loading control. (B) Quantitation of the results of western blot using Image J. Protein levels were normalized to GAPDH. NS: no significant differences, $\mathrm{P}>0.05 ; * * \mathrm{P}<0.01, \mathrm{n}=$ 3. (C) The efficiency of DEPTOR knockdown in HUVECs was tested by western blot. $\beta$-Actin was included as a loading control. (D) Representative photomicrographs of tube formation of HUVECs and quantitation of tube numbers. (E) Representative photomicrographs of the scratching assay in HUVECs at $0 \mathrm{~h}$ and $18 \mathrm{~h}$. The bar graph shows the mean percentage of wound closure. Ctrl: control. NS: no significant differences, $\mathrm{P}>0.05 ; * * \mathrm{P}<0.01, \mathrm{n}=3$. Black bar $=100 \mu \mathrm{m}$.

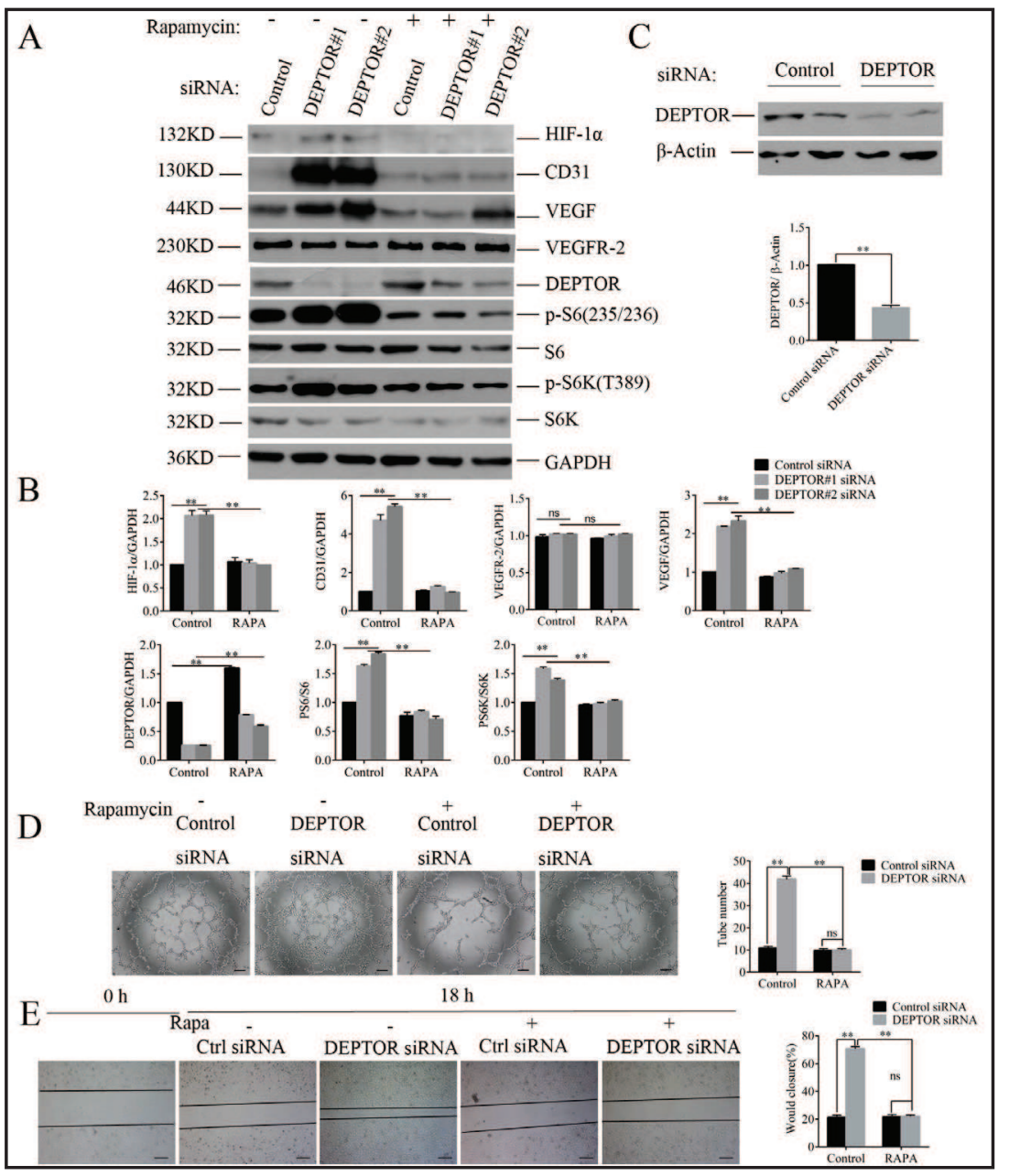

Fig. 7. The effects of DEPTOR overexpression on the mTORC1/HIF-1 $\alpha$ /VEGF pathway in vitro. (A) Western blot analysis of pS6K1 (T389), pS6 (235/236), S6K1, S6, CD31, VEGF, HIF-1 $\alpha$ and GAPDH. GAPDH was included as a loading control. (B) Quantitation of the results of western blots using Image Pro Plus 6.0 software. Protein levels were normalized to GAPDH. NS: no significant differences, $\mathrm{P}>$ $0.05 ; * * \mathrm{P}<0.01, \mathrm{n}=3$.

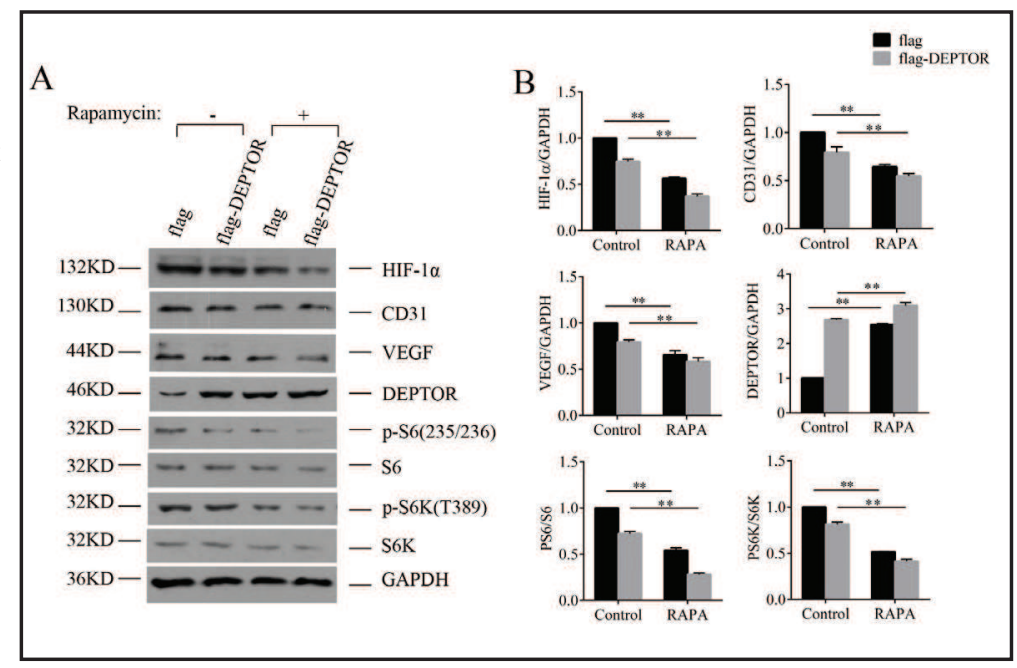

DEPTOR during angiogenesis in vivo and elucidated the underlying mechanisms. First, in order to address the potential role of DEPTOR in vascular homeostasis, mice with a specific 


\section{Cellular Physiology Cell Physiol Biochem 2018;46:520-531 and Biochemistry Published online: April 03, $2018 \quad \begin{aligned} & \text { D 2018 The Authorst } \\ & \text { www.karger.com/cpb }\end{aligned}$ \\ Ding et al.: DEPTOR Deletion in Endothelial Cells Promotes Angiogenesis}

deletion of Deptor in ECs were used in our study. We demonstrated that loss of DEPTOR in ECs promoted angiogenesis through the mTORC1/HIF-1 $\alpha /$ VEGF signaling pathway. The expression of HIF-1 $\alpha$, VEGF and CD31 was notably increased in KO mice accompanied by mTORC1 signaling pathway activation, whereas rapamycin treatment reversed this effect. To further elucidate the role of DEPTOR, in vitro experiments were performed. As expected, small tube formation and migration ability in HUVECs were enhanced after transfection with DEPTOR siRNA, and HIF- $1 \alpha$, VEGF and CD31 expression increased similarly.

The mTOR signaling pathway is important for the expression of HIF-1 $\alpha$ and VEGF [36, 37], and has been shown to regulate the synthesis of HIF- $1 \alpha$ at the translational level [38-40]. As a potent proangiogenic factor, VEGF is involved in the development of several ophthalmic diseases in humans, such as diabetic retinopathy, age-related macular degeneration and retinopathy of prematurity, and HIF- $1 \alpha$ is a major upstream regulator of VEGF [41]. The role of mTOR in the regulation of HIF-1 $\alpha$-mediated VEGF expression has been previously documented [42, 43]. In our results, loss of Deptor resulted in activation of mTORC1 signaling in vascular ECs and subsequently contributed to the promotion of angiogenesis through upregulation of HIF- $1 \alpha$ and VEGF expression. Our study is consistent with previous findings. As a key drug in our experiments, rapamycin is a highly specific inhibitor of mTORC1 and has been used as a clinical immunosuppressant in organ transplantation and as an antiangiogenic agent in clinical trials for treatment of cancers and other vascular diseases $[44,45]$. Interestingly, rapamycin has been reported to inhibit tumor angiogenesis through impairment of HIF-1 $\alpha / \mathrm{VEGF}$ production in some human cancer cell lines [46], which is consistent with our experimental results. In our study, rapamycin treatment efficiently reversed the exaggerated angiogenesis resulting from DEPTOR knockdown.

DEPTOR is an intrinsic inhibitor of mTOR, and can bind not only mTORC1 but also mTORC2. However, in our study, we only focused on the function of mTORC1. The main reason is that mTORC1 may have a more important role in angiogenesis than mTORC2 according to the previous studies. In addition, a recent study found that knockout of DEPTOR did not significantly affect the activity of Akt [18]. This means that loss of DEPTOR has no obvious effect on the mTORC2 pathway. Of course, it does not confirm the role of mTORC2 in angiogenesis and further experiments are needed.

\section{Conclusion}

In summary, our study showed that DEPTOR deficiency mediated mTORC1 hyperactivation in vascular endothelial cells, and thus promoted angiogenesis. Our results suggest that DEPTOR may play a key role in angiogenesis and vascular-related diseases. The mechanism likely involves the mTORC1/HIF-1 $\alpha$ /VEGF signaling pathway, which induced an increase in angiogenesis. Although these results confirmed the importance of mTORC1 activity on angiogenesis in vivo, additional and/or alternate mechanisms cannot be excluded, thus additional future studies are warranted.

\section{Acknowledgements}

This work was supported by grants from the National Natural Sciences Foundation of China $(81530070,81625015,31529002)$ and the Science and Technology Program of Guangzhou, China (201607010081).

\section{Disclosure Statement}

Authors declare no conflicts of interest with the content of this article. 


\section{Cellular Physiology \\ Cell Physiol Biochem 2018;46:520-531 and Biochemistry

\section{References}

1 Birbrair A, Zhang T, Wang ZM, Messi ML, Olson JD, Mintz A, Delbono O: Type-2 pericytes participate in normal and tumoral angiogenesis. Am J Physiol Cell Physiol 2014;307:C25-C38.

-2 Mohammadi E, Nassiri SM, Rahbarghazi R, Siavashi V, Araghi A: Endothelial juxtaposition of distinct adult stem cells activates angiogenesis signaling molecules in endothelial cells. Cell Tissue Res 2015;362:597609.

-3 Chung AS, Lee J, Ferrara N: Targeting the tumour vasculature: Insights from physiological angiogenesis. Nat Rev Cancer 2010;10:505-514.

4 D Alessio A, Moccia F, Li J, Micera A, Kyriakides TR: Angiogenesis and vasculogenesis in health and disease. Biomed Res Int 2015;2015:1-2.

5 Coultas L, Chawengsaksophak K, Rossant J: Endothelial cells and VEGF in vascular development. nature 2005;438:937-945.

-6 Liang L, Yue Z, Du W, Li Y, Tao H, Wang D, Wang R, Huang Z, He N, Xie X, Han Z, Liu N, Li Z: Molecular imaging of inducible VEGF expression and tumor progression in a breast cancer model. Cell Physiol Biochem 2017;42:407-415.

7 Liu N, Zhao N, Cai N: Suppression of the proliferation of hypoxia-Induced retinal pigment epithelial cell by rapamycin through the /mTOR/HIF-1 $\alpha$ /VEGF/ signaling. IUBMB Life 2015;67:446-452.

8 Xiao Y, Peng H, Hong C, Chen Z, Deng X, Wang A, Yang F, Yang L, Chen C, Qin X: PDGF promotes the warburg effect in pulmonary arterial smooth muscle cells via activation of the PI3K/AKT/mTOR/HIF-1 $\alpha$ signaling pathway. Cell Physiol Biochem 2017;42:1603-1613.

-9 Maugeri G, D’Amico AG, Saccone S, Federico C, Cavallaro S, D’Agata V: PACAP and VIP inhibit HIF-1 $\alpha$ Mediated VEGF expression in a model of diabetic macular edema. J Cell Physiol 2016;9999:1-7.

$\checkmark 10$ Dormond O, Madsen JC, Briscoe DM: The effects of mTOR-Akt interactions on anti-apoptotic signaling in vascular endothelial cells. J Biol Chem 2007;282:23679-23686.

-11 Reinders MEJ, Rabelink TJ, Briscoe DM: Angiogenesis and endothelial cell repair in renal disease and allograft rejection. J Am Soc Nephrol 2006;17:932-942.

-12 Guba M, von Breitenbuch P, Steinbauer M, Koehl G, Flegel S, Hornung M, Bruns CJ, Zuelke C, Farkas S, Anthuber M, Jauch KW, Geissler EK: Rapamycin inhibits primary and metastatic tumor growth by antiangiogenesis: Involvement of vascular endothelial growth factor. Nat Med 2002;8:128-135.

-13 Phung TL, Ziv K, Dabydeen D, Eyiah-Mensah G, Riveros M, Perruzzi C, Sun J, Monahan-Earley RA, Shiojima I, Nagy JA, Lin MI, Walsh K, Dvorak AM, Briscoe DM, Neeman M, Sessa WC, Dvorak HF, Benjamin LE: Pathological angiogenesis is induced by sustained Akt signaling and inhibited by rapamycin. Cancer Cell 2006;10:159-170.

-14 Pazoki-Toroudi H, Amani H, Ajami M, Nabavi SF, Braidy N, Kasi PD, Nabavi SM: Targeting mTOR signaling by polyphenols: A new therapeutic target for ageing. Ageing Res Rev 2016;31:55-66.

15 Laplante M, Sabatini DM: MTOR signaling in growth control and disease. Cell 2012;149:274-293.

16 Liu SQ, Zhao JP, Fan XX, Liu GH, Jiao HC, Wang XJ, Sun SH, Lin H: Rapamycin, a specific inhibitor of the target of rapamycin complex 1, disrupts intestinal barrier integrity in broiler chicks. J Anim Physiol An N 2016;100:323-330.

17 Duan S, Shafi JRS, Kuchay S, Toschi A, Kanarek N, Ben-Neriah Y, Pagano M, Pagano AM: MTOR generates an Auto-Amplification loop by triggering the bTrCP- and CK1a-Dependent degradation of DEPTOR. Mol Cell 2011;44:317-324.

18 Bruneau S, Nakayama H, Woda CB, Flynn EA, Briscoe DM: DEPTOR regulates vascular endothelial cell activation and proinflammatory and angiogenic responses. Blood 2013;122:1833-1842.

19 Chen W, Lai S, Yu D, Liu J, Jiang S, Zhao D, Ding Y, Li C, Xue B: GGPPS deficiency aggravates CCl4-induced liver injury by inducing hepatocyte apoptosis. Febs Lett 2015;589:1119-1126.

-20 Peterson TR, Laplante M, Thoreen CC, Sancak Y, Kang SA, Kuehl WM, Gray NS, Sabatini DM: DEPTOR is an mTOR inhibitor frequently overexpressed in multiple myeloma cells and required for their survival. Cell 2009;137:873-886.

21 Wong AL, Haroon ZA, Werner S, Dewhirst MW, Greenberg CS, Peters KG: Tie2 expression and phosphorylation in angiogenic and quiescent adult tissues. Circ Res 1997;81:567-574.

22 Ma A, Wang L, Gao Y, Chang Z, Peng H, Zeng N, Gui YS, Tian X, Li X, Cai B, Zhang H, Xu KF: Tsc1 deficiencymediated mTOR hyperactivation in vascular endothelial cells causes angiogenesis defects and embryonic lethality. Hum Mol Genet 2014;23:693-705.

23 Prodromidis G, Nikitakis NG, Sklavounou A: Immunohistochemical analysis of the activation status of the Akt/mTOR/pS6 signaling pathway in oral lichen planus. Int J Dent 2013;2013:1-15. 


\section{Cellular Physiology Cell Physiol Biochem 2018;46:520-531

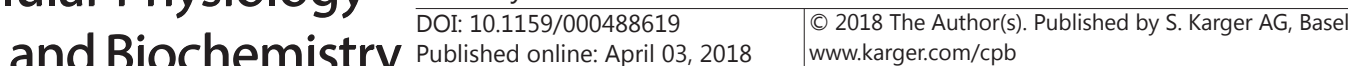 and Biochemistry

Ding et al.: DEPTOR Deletion in Endothelial Cells Promotes Angiogenesis

24 Park J, Yoon J, Park B: Pomolic acid suppresses HIF1 $\alpha /$ VEGF-mediated angiogenesis by targeting p38MAPK and mTOR signaling cascades. Phytomedicine 2016;23:1716-1726.

25 Zhao Q Wang Z, Wang Z, Wu L, Zhang W: Aspirin may inhibit angiogenesis and induce autophagy by inhibiting mTOR signaling pathway in murine hepatocarcinoma and sarcoma models. Oncol Lett 2016;12:2804-2810.

-26 Li L, Pan H, Wang H, Li X, Bu X, Wang Q Gao Y, Wen G, Zhou Y, Cong Z, Yang Y, Tang C, Liu Z: Interplay between VEGF and Nrf2 regulates angiogenesis due to intracranial venous hypertension. Sci Rep-Uk 2016;6:37338.

27 Wu J, Ke X, Wang W, Zhang H, Ma N, Fu W, Zhao M, Gao X, Hao X, Zhang Z: Aloe-emodin suppresses hypoxiainduced retinal angiogenesisvia inhibition of HIF-1 $\alpha$ /VEGF pathway. Int J Biol Sci 2016;12:1363-1371.

28 Das F, Bera A, Ghosh-Choudhury N, Abboud HE, Kasinath BS, Choudhury GG: TGFb-Induced deptor suppression recruits mTORC1 and not mTORC2 to enhance collagen i(a2) gene expression. Plos One 2014;9:e109608.

29 Vadlapatla RK, Vadlapudi AD, Pal D, Mukherji M, Mitra AK: Ritonavir inhibits HIF-1 $\alpha$-mediated VEGF expression in retinal pigment epithelial cells in vitro. Eye 2013;28:93-101.

-30 Laplante M, Sabatini DM: MTOR signaling. Csh Perspect Biol 2012;4:a11593.

-31 Liu M, Wilk SA, Wang A, Zhou L, Wang RH, Ogawa W, Deng C, Dong LQ, Liu F: Resveratrol inhibits mTOR signaling by promoting the interaction between mTOR and DEPTOR. J Biol Chem 2010;285:36387-36394.

-32 Ji YM, Zhou XF, Zhang J, Zheng X, Li SB: DEPTOR suppresses the progression of esophageal squamous cell carcinoma and predicts poor prognosis. Oncotarget 2016;7:14188-14198.

-33 Chen L, Liu T, Tu Y, Rong D, Cao Y: Cul1 promotes melanoma cell proliferation by promoting DEPTOR degradation and enhancing cap-dependent translation. Oncol Rep 2016;35:1049-1056.

34 González-Terán B, López JA, Rodríguez E, Leiva L, Martínez-Martínez S, Bernal JA, Jiménez-Borreguero LJ, Redondo JM, Vazquez J, Sabio G: P38 $\gamma$ and $\delta$ promote heart hypertrophy by targeting the mTOR-inhibitory protein DEPTOR for degradation. Nat Commun 2016;7:10477.

-35 Li L, Hu M, Zheng L, Zhang C, Li J, Rong R, Zhu T, Jia Y: Endothelin receptor Down-Regulation mediated ligand regulation mechanisms protect against cellular hypoxia injury in rat vascular endothelial cells. Cell Physiol Biochem 2016;40:1443-1454.

-36 Scott CL, Walker DJ, Cwiklinski E, Tait C, Tee AR, Land SC: Control of HIF-1 $\alpha$ and vascular signaling in fetal lung involves cross talk between mTORC1 and the FGF-10/FGFR2b/Spry2 airway branching periodicity clock. AJP: Lung Cell Mol Physiol 2010;299:L455-L471.

-37 Wei J, Jiang H, Gao H, Wang G: Blocking mammalian target of rapamycin (mTOR) attenuates HIF-1 $\alpha$ pathways Engaged-Vascular endothelial growth factor (VEGF) in diabetic retinopathy. Cell Physiol Biochem 2016;40:1570-1577.

38 Wang F, Zhang W, Guo L, Bao W, Jin N, Liu R, Liu P, Wang Y, Guo Q, Chen B: Gambogic acid suppresses hypoxia-induced hypoxia- inducible factor- $1 \alpha /$ vascular endothelial growth factor expression via inhibiting phosphatidylinositol 3-kinase / Akt / mammalian target protein of rapamycin pathway in multiple myeloma cells. Cancer Sci 2014;105:1063-1070.

-39 Agrawal R, Pandey P, Jha P, Dwivedi V, Sarkar C, Kulshreshtha R: Hypoxic signature of microRNAs in glioblastoma: Insights from small RNA deep sequencing. Bmc Genomics 2014;15:686.

40 Masson N, Ratcliffe PJ: Hypoxia signaling pathways in cancer metabolism: The importance of co-selecting interconnected physiological pathways. Cancer Metab 2014;2:3.

-41 Sarkar K, Rey S, Zhang X, Sebastian R, Marti GP, Fox-Talbot K, Cardona AV, Du J, Tan YS, Liu L, Lay F, Gonzalez FJ, Harmon JW, Semenza GL: Tie2-dependent knockout of HIF-1 impairs burn wound vascularization and homing of bone marrow-derived angiogenic cells. Cardiovasc Res 2011;93:162-169.

42 Lee HP, Lin CY, Shih JS, Fong YC, Wang SW, Li TM, Tang CH: Adiponectin promotes VEGF-A-dependent angiogenesis in human chondrosarcoma through PI3K, Akt, mTOR, and HIF-alpha pathway. Oncotarget 2015;6:36746-36761.

-43 Xie X, Ma L, Xi K, Zhang W, Fan D: MicroRNA-183 suppresses neuropathic pain and expression of AMPA receptors by targeting mTOR/VEGF signaling pathway. Cell Physiol Biochem 2017;41:181-192.

-44 Pospelova TV, Bykova TV, Zubova SG, Katolikova NV, Yartzeva NM, Pospelov VA: Rapamycin induces pluripotent genes associated with avoidance of replicative senescence. Cell Cycle 2013;12:3841-3851.

45 Blagosklonny MV: Rapamycin extends life- and health span because it slows aging. Aging (Albany NY) 2013;5:592-598.

-46 Ion A, Popa IM, Papagheorghe LML, Lisievici C, Lupu M, Voiculescu V, Caruntu C, Boda D: Proteomic approaches to biomarker discovery in cutaneous T-Cell lymphoma. Dis Markers 2016;2016:1-8. 